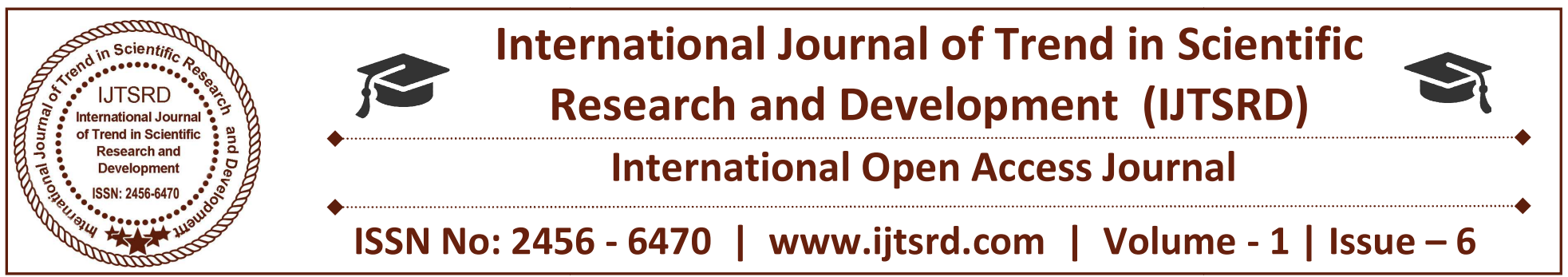

\title{
A Review on Experimental Analysis of Double Pass Solar Air Heater With Baffled Absorber Plate
}

\author{
Vivek Singh \\ M.E. Scholar,Mechanical Engg., \\ Radharaman Institute of \\ Technology and Science, \\ Bhopal, M.P.
}

\author{
Ajay Singh \\ Head and Professor, Department of \\ Mechanical Engg., Radharaman \\ Institute of Technology and \\ Science, Bhopal, M.P.
}

\author{
Ashish Verma \\ Assistant Professor, Department of \\ Mechanical Engg., Radharaman \\ Institute of Technology and \\ Science, Bhopal, M.P.
}

\section{ABSTRACT}

This review paper based on the study of different type of solar air heater with baffled fin and without using baffle fin. It has been observed that the thermal efficiency of baffled duct type solar air heater is higher than smooth duct solar air heater. Highest thermal performance advantage in wide range of air flow rate. The heat transfer coefficient between the absorber plate and air can be considerably increased by using artificial roughness on the bottom plate and under the absorber plate of a solar air heater duct. Study and analysis of roughness and operating parameters on heat transfer. The study has covered the range of Reynolds number Re depending on types of the configuration of the solar collectors. Based on the values of Nusselt number $\mathrm{Nu}$ have been determined for different values of configurations and operating parameters. To determine the increase in heat transfer and increment in thermal performance, the values of Nusselt have been compared with those of smooth duct and baffled fin under similar flow conditions. The enhancement is attributed to the heat transfer increases due to the perforated baffles on the absorber plate and reduction in the mean absorber plate temperature.

Keyword: solar air heater, blower, Baffled plate, thermal efficiency

\section{INTRODUCTION}

Several studies in forced convection heat transfer for smooth and baffle ducts, and much useful information is available in the research paper. The use of artificial roughness on a surface is an effective way to increases heat transfer to fluid flowing in ducts. In this study, two modes of the baffle fin are tested under and on an absorber plate. Both, absorber plate and bottom plate of solar air heaters having transversal baffle with rectangular form on one side of the plate (flow side) give better thermal performance than smooth plate. For converting the flow to turbulent, artificial roughness are to be used. Turbulent flow breaks the laminar boundary layer so it increases in thermal performance. Thus, the artificial roughness can be used for the increases of heat transfer coefficient between the absorber plate and air, thereby improving the thermal performance of solar air heaters (SAHs).Solar air collector is use for space heating and other purposes. Studies show that the efficiency of solar air collector can be improved by designing the baffle fin and artificial roughness. The solar air collectors, are very simple in design and cheaper so it extensively used in the world for heating purposes. In this study, a test of solar air collector was performed based on the heating of air by different configurations of the roughness, and the surface area for heat exchange. Baffle fin with rectangular form is one of the best important and attractive in design 
improvements proposed to increase thermal performance. Investigated theoretically and experimentally the effect of parallel barriers on the collector efficiency of flat-plate SAHs and discovered that the collector efficiency increases theoretically as the number of barriers increases [21]. Experimentally investigated the forced convection heat transfer at an inclined and yawed square plate. The common practice in predicting performance of solar energy system is to solve a set of several inter-related [27]. The convective heat transfer coefficient, h (absorber plate to flowing air) is an important parameter required for mathematical modeling, computer simulation and performance prediction [26]. Many researchers, while predicting the performance of solar dryers systems, are constrained to utilize convective heat transfer correlations published for standard geometries of system and specific test conditions [28, 29]. Comparison of results reveals that the thermal efficiency of a single pass is higher with an increase in the flow rate. Increasing the absorber area or fluid flow heat-transfer area will increase the heat transfer to the flowing air and the pressure drop in the collector [10]. On the other hand, several configurations of absorber plates have been designed to improve the heat transfer coefficient. Artificial roughness obstacles and baffles in various shapes and arrangements were employed to increase the area of the absorber plate. As a result, the heat transfer coefficient between the absorber plate and the air pass is improved [24]. Conducted an experimental investigation of the thermal performance of a single and double pass SAH with fins attached and a steel wire mesh as absorber plate [15,27]. The result of a single or double SAH, when compared with conventional SAH, shows much more substantial enhancement in thermal efficiency. Numerically studied the performance and entropy generation of the double-pass flat plate SAH with longitudinal fins [18].The fins served as heat transfer augmentation features in SAHs however, they increased the pressure drop in flow channels. The results showed that high efficiency of the optimized fin improved the heat absorption and dissipation potential of a SAH [30]. The double flow SAH was designed with fins attached over and under the absorbing plate. This resulted in a considerable improvement in collector efficiency of double flow SAHs with fins compared to single flowing, operating at the same flow rate [2,27]. An experimental investigation was carried out on the thermal performance of the offset rectangular plate fin absorber plates with various glazing [2], in which, the offset rectangular plate fins which were used in heat exchangers, were experimentally studied. Because the offset rectangular plate fins were mounted in staggered pattern and oriented parallel to the fluid flow, high thermal performances were obtained with low-pressure losses. Conducted experiments to study the performance of three types of $\mathrm{SAH}$, namely flat plate, finned and V-corrugated SAHs.The Vcorrugated collector was found to be the most efficient while the flat plate collector the least efficient $[25,17,5]$. Another work used the crosscorrugated absorbing plate and bottom plate to enhance the turbulence and the heat transfer rate inside the air flow channel and tested its thermal performance [7]. A novel solar air collector of pin-fin integrated absorber was designed to increase the thermal efficiency in the performance analysis of varying flow rates on pin-fin arrays collector, the correlation equation for the heat transfer coefficient was obtained and the efficiency variation vs. air flow rate was determined. In another work, the results were compared with those obtained with a solar air collector without fins, using two types of absorbers selective (in copper sun) or not selective (blackpainted aluminum)[20]. Presented a solar water heater designed with a local vegetable material as insulating material. They focused on the comparative thermal performance of this collector and another collector, identical in design, fabrication, and operating under the same conditions, using glass wool as heat insulation[31]. Studied the effect of the mass flow rate in the solar collector with longitudinal fins[10]. The flat-plate SAH was considered to be a simple device consisting of one (transparent) cover situated above an absorbing plate with the air flowing under the absorber plate [9]. The conventional flat-plate SAH was investigated for heat transfer efficiency improvement by introducing forced convection $[32,33]$ extended heat-transfer area $[15,22,23]$ and increase of air turbulence [10]. The value of a convection heat transfer coefficient depends upon the physical configuration as well as upon several properties of the fluid occupied. Empirical correlations are available to estimate heat transfer coefficients for a variety of forced convection heat transfer configurations and will be presented and discussed in this study. It was found that the optimal value of efficiency was determined by the SAH with absorbent plate in flow channel duct for all operating conditions and the collector supplied with obstacles appeared significantly better than that without obstacles. 


\section{Types of Solar Air Heater}

SAH collects incident solar radiant energy into heat through a fluid flowing inside the system. The concept indicates that the fluid flows through a solar collector and heat from the sun naturally increases the temperature of fluid (the air) up to a certain level $[1,9,10]$. In other words, cold air heated by the help of solar air collector and transfer to desire space. There are so many types of collector used in solar heating purpose and one most type of solar air heater. [1] L.B.Y. Aldabbagh a, F. Egelioglu a, ${ }^{*}$, M. Ilkan b Single and double pass solar air heaters with wire mesh as packing bed. The collector has an outer layer of glazing exposing to the sun. Preheated air supplied to the buildings had developed a good interest during the few past decades. The advantage of this technology is that It is costly and simple. It is exclusively effective for summer houses as it can work without a particular attention. In this way, the indoor environment of household and other building is maintained at a good level in cold climates. Mahmud M. Alkilani et al. [4] Review of solar air collectors with thermal storage units and it result it increases thermal performance. Basically, all SAHs can be classified under two categories [20], while a detailed classification has also been shown in below.

1. Air heaters with non-porous absorber plate and

2. Air heaters with porous absorber plate.

1. Air heaters with non- porous absorber plate In this type, the air stream does not flow through the absorber tray. The air may flow above or beneath the absorber tray.

Samir A. Dhatkar et el. [8] A Review of Solar Air Heaters using wire Mesh Absorber. The air that blows above the absorber surface increased the convection loss from the cover plate and therefore it is avoided, if the ' $\mathrm{T}$ ' and size at the collector are large. Selective coating can be applied to improve collector efficiency.

These can be classified as [20];

1. Conventional air heater,

2. Air heaters with fins,

3. Vee-corrugated air heater,

4. Double exposure heaters,

5. Double flow solar air heater and

6. Two pass solar air heater.
2. Air heaters with porous absorber A major disadvantage of the nonporous absorber is the necessity of capturing all incoming solar radiation over the projected area through a thin layer over the absorber's surface. B.M. Ramani a, Akhilesh Gupta b, ${ }^{*}$, Ravi Kumar b [18] Performance of a double pass solar air collector. If some selective coatings are used then radiative losses from the absorber can be minimized and unless the collection efficiency remains poor. The $\Delta \mathrm{P}$ along the duct formed between the absorber plate and there insulation may also be prohibitive, especially in the case of added fins to increase the heat transfer area and turbulence rate. The porous absorber SAHs can be classified as given below [14-17];

\section{Packed bed solar air heater,}

2. Overlapped glass plate air heater,

3. Matrix air heater,

4. Honeycomb porous bed air heater and

5. All plastic solar air heaters.

\section{Description of Baffled Fin}

A view of the constructed single flow under an absorber plate in duct of solar collector is shown Fig and the schematic of a solar collector and the view of the absorber plate in the collector box are demonstrated in Fig. In many research paper observed that with baffled duct is more efficient than without baffled duct and seen that rectangular baffled manly used in experiment .In this study, three configurations of the absorber plates were used with baffle fin fixed on the absorber plate and on the bottom plate. The absorbers were made of galvanized iron sheet with black chrome selective coating. The plate thicknesses of three collectors are same. Single transparent cover was used for the three collectors. Thermal losses through the collector backs were mainly caused by the conduction across the insulation and those caused by the wind and the thermal radiation of the insulation were assumed to be negligible. After installation, the two collectors were left operating for several days under normal weather conditions for weathering processes. The thermocouples were positioned evenly on the top surface of the absorber plates, at identical positions along the direction of flow for both collect. 

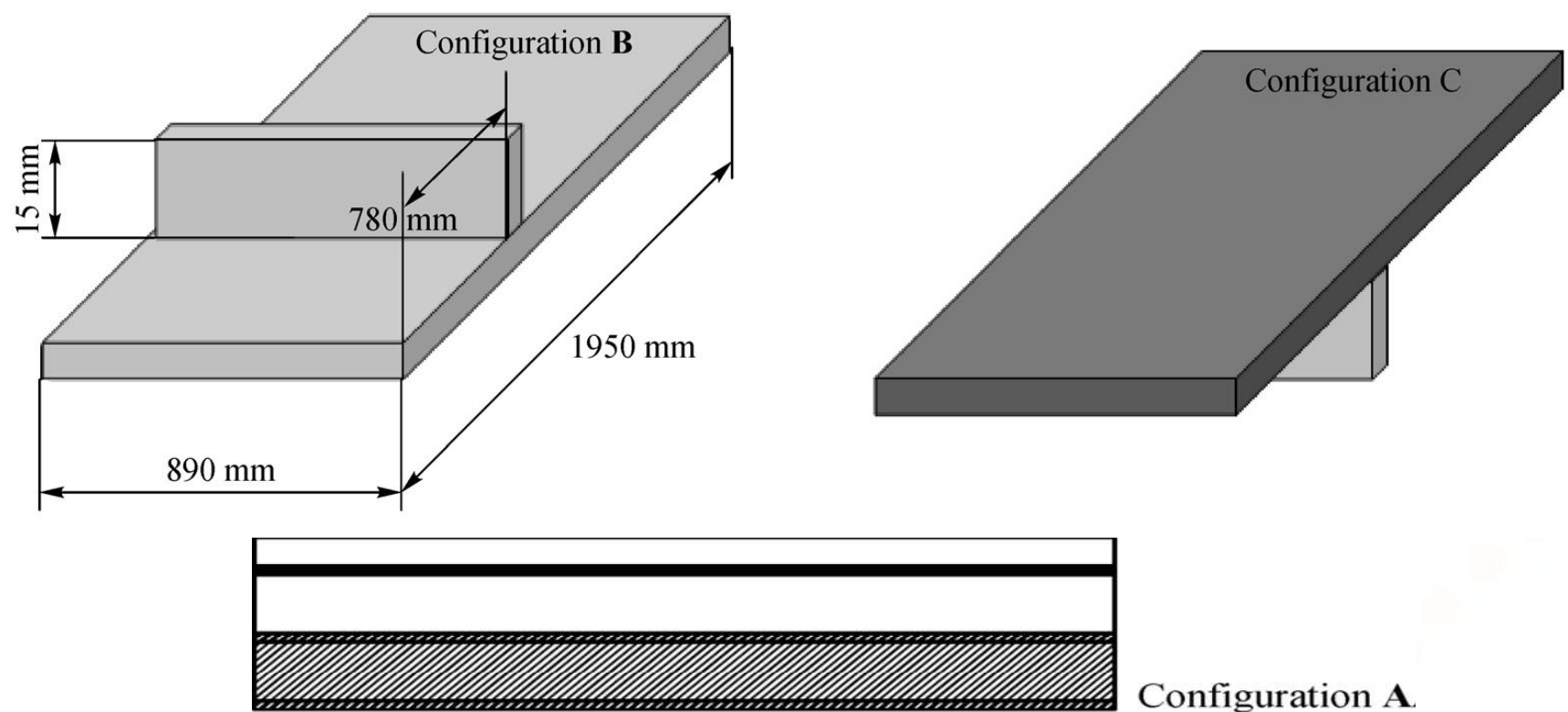

Configuration $\mathbf{A}$

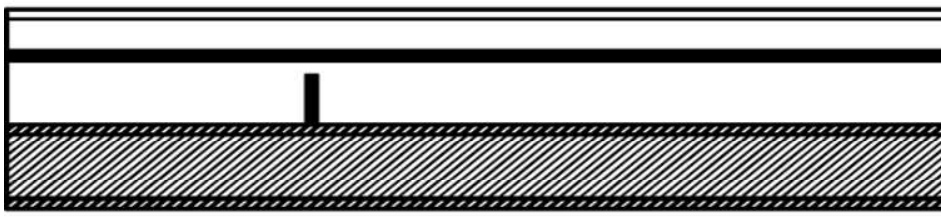

Configuration B

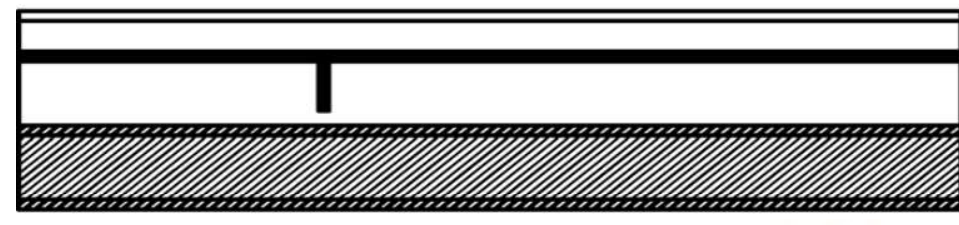

Configuration C:

\section{CONCLUSIONS}

The present studied aims to analyze a thermal efficiency of SAH. The comparison of solar collectors with smooth plate and with baffled duct indicates that the efficiency of the solar air collector depends on the solar radiation, the volume flow rate and the position of a baffle when is fixed on the duct of solar collectors. The efficiency of the collector improves by increasing the volume flow rate due to increase heat transfer to the air flow. The thermal performance of the solar air collector to be higher. Baffled collector with tild angle to achieve high thermal efficiency and outlet temperature. Whereas the lowest values were obtained from the collector with smooth plate. following conclusions can be drawn:

1. Air mass flow rate and solar radiation are effective factors which affect the performance of SAH.

2. The thermal efficiency of the baffled duct solar air heater is higher than the smooth duct solar air heater.

\section{REFERENCES}

1) Single and double pass solar air heaters with wire mesh as packing bed. L.B.Y. Aldabbagh, F. Egelioglu, M. Ilkan.

2) Foued CHABANE, Nesrine HATRAF, Noureddine MOUMMI Experimental study of heat transfer coefficient with rectangular baffle fin of solar air heater.

3) Review on matrix thermal absorber designs for solar air collector A.A.Razak , Z.A.A.Majid , W.H.Azmi , M.H.Ruslan , Sh.Choobchiane, G.Najafi , K. Sopian.

4) Review of solar air collectors with thermal storage units.Mahmud M. Alkilani , K. Sopian, M.A. Alghoul, M. Sohif, M.H. Ruslan.

5) Experimental investigation on performance of a double pass artificial roughened solar air heater duct having roughness elements of the combination of discrete multi $\mathrm{V}$ shaped and staggered ribs. Ravi Kant Ravi, R.P. Saini Alternate Hydro Energy Centre, Indian Institute of 
Technology Roorkee, Roorkee, Uttarakhand 247667, India.

6) Efficiency Enhancement of Two Pass Solar Collector with Steel Matrix in the Region of Rajshahi, Bangladesh Article May.

7) A parametric study on the thermal performance of cross-corrugated solar air collectors.

8) A Review of Solar Air Heaters using wire Mesh Absorber Samir Dhatkar, Ankit Khandelwal, Kanase-Patil.

9) Integration of transparent insulation materials into solar collector devices. Julian D. Osorio, Alejandro Rivera-Alvarez, Philibert Girurugwiro, Sam Yang, Rob Hovsapian.

10) Thermal efficiency analysis of a single flow solar air heater with different mass flow rate in a smooth plate. Foued Chabanea, Noureddine Moummi, Abdelhafid Brima, Said Benramache.

11) Solar air heater with phase change material: An energy analysis and acomparative study Aymen El Khadraoui , Salwa Bouadila, Sami Kooli, Amenallah Guizani, Abdelhamid Farhat.

12) Performance and Cost Aspect of Double Pass V Groove Absorber with and without Porous Media. Article December 2016.

13) A Review of Recent Patents on Solar Air Heaters Article. April 2015.

14) Greenhouse heating by solar air heaters on the roof. Khalid A. Joudi, Ammar A. Farha.

15) Recycle Effect on Device Performance of Wire Mesh Packed Double-Pass Solar Air Heaters. Chii-Dong Ho, Chun-Sheng Lin, Tz-Jin Yang and Chun-Chieh Chao.

16) Low cost solar air heater. R.S. Gill, Sukhmeet Singh, Parm Pal Singh.

17) Thermal Performance of Recycle Pass Solar Air Heater with V... Article September 2016.

18) Performance of a double pass solar air collector. B.M. Ramani, Akhilesh Gupta, Ravi Kumar .

19) Matrix solar air heaters - A review K. Rajarajeswari, A.Sreekumar.

20) A thermodynamic review of solar air heaters. Abhishek Saxena, Varun, A.A.El-Sebaii Faculty of Mechanical Engineering ,M.I.T., Moradabad244001 ,India.Faculty of Mechanical Engineering, N.I.T., Hamirpur177005, India c Physics Department, Faculty of Science, Tanta University, Tanta ,Egypt.

21) Experimental investigation of thermal performance of a double-flow solar air heater having aluminium cans. Filiz Ozgen, Mehmet Esen, Hikmet Esen.
22) Performance Analysis of Double Pass Solar Air Heater with Bottom Extended Surface. Rudra Nandan Pramanika,, Sudhansu Sekhar Sahoob, Ranjan Kumar Swainc,Tara Prasad, Mohapatraa, Ashis Kumar Srivastava.

23) Experimental Investigation of Single Pass Solar Air heater With and Without Square Steel Wire Mesh on Absorber plate Conference Paper December 2016

24) Comparative Study of Thermo-Hydraulic Performance of Artificially Roughened Solar Air Heaters Conference Paper February 2014.

25) Performance and Cost Aspect of Double Pass V Groove Absorber with and without Porous Media Article

26) Performance Study of Solar Air Heater with Baffled Duct. B.K. Maheshwari, Rajendra Karwa, R. Singhvi, A. Goyal, R.N. Kumawat, A. Sharma, R. Prajapat, D. Kumawat, M. Rankawat, N. Bhardwaj.

27) Collector Efficiency by Single Pass of Solar Air Heaters with and without Using Fins Foued Chabane, Noureddine Moummi, Said Benramache, Djamel Bensahal and Okba Belahssen

28) Garg H P, Kumar R. Studies on semi-cylindrical solar tunnel dryers: thermal performance of collector. Applied Thermal Engineering,2000, 20(2): 115-131

29) Smitabhindu R, Janjai S, Chankong V. Optimization of a solarassisted drying system for drying bananas. Renewable Energy,200833(7): $1523-1531$

30) Nwosu N P. Employing exergy-optimized pin fins in the design of an absorber in a solar air heater. Energy, 2010, 35(2): 571-575

31) Andoh H Y, Gbaha P, Koua B K, Koffi P M E, Touré S. Thermal performance study of a solar collector using a natural vegetable fiber, coconut coir, as heat insulation. Energy for Sustainable Development, 2010, 14(4): 297-301

32) Duffie J A, BeckmanWA. Solar Engineering of Thermal Processes,3rd ed. John Wiley \& Sons, 2006

33) Tonui J K, Tripanagnostopoulos Y. Improved $\mathrm{PV} / \mathrm{T}$ solar collectors with heat extraction by forced or natural air circulation. Renewable Energy, 2007, 32(4): 623-637. 